\title{
Formação de classes ordinais após a aprendizagem de seqüências independentes
}

\author{
Ana Claudia Moreira Almeida Verdu \\ Universidade Estadual Paulista - Bauru \\ Deisy das Graças de Souza \\ Universidade Federal de São Carlos \\ Jair Lopes Junior \\ Universidade Estadual Paulista - Bauru
}

\begin{abstract}
Resumo
A aquisição de relações ordinais entre estímulos arbitrários é uma importante habilidade comportamental, requisito para a aprendizagem de comportamentos acadêmicos, especialmente a alfabetização. O propósito deste estudo foi investigar o efeito do ensino de seqüências de dois termos com sobreposição na emergência de relações ordinais com mais de dois estímulos. A sobreposição ocorre quando o último estímulo em uma seqüência de dois estímulos é o primeiro de outra seqüência (e.g., S1 $\rightarrow$ S2 e S2 $\rightarrow$ S3, onde S2 é o estímulo sobreposto). Nas Etapas 1 e 2 de um experimento conduzido com cinco estudantes do ensino fundamental foram ensinadas seqüências de dois termos com os cinco estímulos de um conjunto $\mathrm{A}(\mathrm{A} 1 \rightarrow \mathrm{A} 2$, A2 $\rightarrow \mathrm{A} 3$, A3 $\rightarrow$ A4, A4 $\rightarrow$ A5) e os cinco de um conjunto B (B1 $\rightarrow$ B2, B2 $\rightarrow$ B3, B3 $\rightarrow$ B4, B4 $\rightarrow$ B5). Estabelecida essa linha de base, foram conduzidos testes da emergência de relações ordinais com três, quatro e cinco termos dos conjuntos A e B, separadamente. A Etapa 3 avaliou se estímulos das seqüências ensinadas eram mutuamente substituíveis, com base na mesma função ordinal (primeiro, secundo, etc.). Os estudantes compuseram as relações ordinais ensinadas e apresentaram relações ordinais emergentes com estímulos dos conjuntos A e $\mathrm{B}$, separadamente. Três estudantes também realizaram a substituição mútua entre estímulos dos conjuntos A e B na Etapa 3. Esses resultados sugerem a formação de cinco classes de estímulos (A1B1, A2B2, etc.), cada uma consistindo de estímulos que ocuparam a mesma função ordinal em diferentes seqüências. Os resultados têm implicações para a análise de comportamento simbólico complexo. Merecem consideração, também, aspectos metodológicos que favoreceram a aprendizagem relacional e a emergência de comportamento novo.
\end{abstract}

Palavras-chave: relações ordinais; classes de estímulos; comportamento simbólico; ensino fundamental.

\begin{abstract}
The formation of ordinal classes derived from learning independent sequences. The acquisition of ordinal relations between arbitrary stimuli is an important behavioral skill required in learning academic behaviors and literacy. The purpose of this study was to investigate the effects of teaching overlapping adjacent twoterm sequences on the emergence of ordinal relations with more than two stimuli. Overlapping occurs when the last stimulus in one sequence of two stimuli is the first stimulus in another sequence (e.g., S1 $\rightarrow$ S2 and $\mathrm{S} 2 \rightarrow \mathrm{S} 3$, where S2 is the overlapped stimulus). Two-term sequences were taught in Phases 1 and 2 of an experiment conducted with five first grade students. Sequences A were taught with stimuli from sets A (A1 $\rightarrow$ A2, A2 $\rightarrow$ A3, A3 $\rightarrow$ A4, A4 $\rightarrow$ A5) and Sequences B with stimuli from set B (B1 $\rightarrow$ B2, B2 $\rightarrow$ B3, B3 $\rightarrow$ B4, B4 $\rightarrow$ B5). Once this baseline was established, tests verified the emergence of ordinal relations with three, four and five stimuli from sets A and B, separately. Phase 3 evaluated if stimuli from Sequences A and B were substitutable one for one another, on the basis of the same ordinal functions (the first, the second, etc.). The students learned all trained ordinal relations and showed the emergence of new (and longer) ordinal relations with stimuli of sets A and B stimuli, separately. Three students also showed substitutability between A and B stimuli in Phase 3. These findings suggest the formation of five stimuli classes, each one consisted of stimuli that occupied the same ordinal function in different sequences. These results suggest the emergence of five stimulus classes (A1B1, A2B2, etc), each one with stimuli that occupied the same ordinal function in different sequences. The results have implications for the analysis of complex symbolic behavior. Some methodological aspects seemed to have contributed for the occurrence of relational learning and the emergence of novel behavior.
\end{abstract}

Keywords: ordinal relations; stimulus classes; symbolic behavior; first grade 
$\mathrm{O}$ estabelecimento de relações ordinais entre eventos tem significativa importância no âmbito das habilidades necessárias para o domínio de conteúdos previstos no ensino fundamental. A exemplo disso, sentenças como "Segunda-feira vem antes de terça-feira", "Terça-feira vem antes de quarta-feira", "Quarta-feira vem antes de quinta-feira" e "Quinta-feira vem antes de sexta-feira”, expressam a organização de eventos em função de uma determinada ordem. Do ponto de vista dos processos comportamentais envolvidos na aprendizagem de relações ordinais, constitui-se um tópico de investigação verificar se a organização de eventos em função de uma ordem particular consiste em estabelecer respostas encadeadas a estímulos ou se, diferentemente, poderia corresponder à emergência ou manifestação de novas relações, a partir de outras relações previamente ensinadas.

Investigações experimentais nos cenários nacional e internacional têm fornecido suporte para esta última posição, ainda que pela utilização de procedimentos distintos (Assis \& Costa, 2004; Assis, Élleres, \& Sampaio, 2006; Assis \& Sampaio, 2003; Green, Stromer, \& Mackay, 1993; Holcomb, Stromer, \& Mackay, 1997; Lazar, 1977; Lima \& Assis, 2003; Maydak, Stromer, Mackay, \& Stoddard, 1995; Stromer \& Mackay, 1993). De modo análogo aos dados produzidos por tais investigações e considerando o exemplo acima enunciado, teríamos, a partir do ensino daquelas sentenças, a emergência (manifestação sem uma história de ensino explícita ou direta) de novas relações como "segunda, terça, quarta, quinta e sexta-feira", nesta ordem, ou ainda, se segunda vem antes de terça e terça vem antes de quarta, então segunda vem antes de quarta. Esses tipos de repertórios envolvem propriedades que não são específicas e inerentes aos estímulos, mas sim, caracterizam respostas apresentadas na presença de estímulos que se relacionam segundo uma ordem (relações ordinais) no tempo e ou no espaço.

A emergência de novas relações que não participam de uma história de ensino explícita constitui-se em objeto de investigações teóricas e, principalmente, empíricas. A preocupação concentra-se na análise funcional de comportamentos complexos, como os exigidos em contextos acadêmicos, dentre os quais, o estabelecimento de relações ordinais entre estímulos. Os processos comportamentais derivados dessas situações de ensino podem ser a base para a aquisição e desenvolvimento de repertórios que a escola requer com freqüência, como por exemplo, relações sintáticas (Assis, Élleres, \& Sampaio, 2004) ou conceitos de matemática (Carmo \& Prado, 2004). Uma criança que tenha sido ensinada a dizer "corda grande", "boneca bonita" e "bola colorida” pode produzir novas expressões gramaticalmente corretas sem treino explícito, pela permutação de palavras que ocorrem em uma mesma posição em seqüências estabelecidas em separado (por exemplo, "bola bonita”, “corda colorida”, "boneca grande”).

Estudos experimentais têm demonstrado que esses repertórios que definem a formação de classes fundamentadas em relações ordinais emergem sob condições de ensino bem específicas (Holcomb et al. 1997; Lazar, 1977; Maydak et al. 1995; Stromer \& Mackay, 1993).
Lazar (1977) investigou os efeitos do ensino de pares de seqüências no estabelecimento de classe de estímulos definidas por relações ordinais, o que poderia ser demonstrado pela permutação de eventos com base meramente na posição que ocupavam nas seqüências originalmente ensinadas. Para isso, Lazar (1977) ensinou três adultos com desenvolvimento típico a apontar, em seqüência, cada um dos dois membros de quatro pares de estímulos visuais arbitrários, apresentados em cartões. A tarefa do participante era selecionar primeiro um estímulo e depois o outro (A1 $\rightarrow$ A2, B1 $\rightarrow$ B2, C1 $\rightarrow$ C2 e $\mathrm{D} 1 \rightarrow \mathrm{D} 2)^{1}$. Todos os participantes aprenderam a apontar os pares de estímulos apresentados nos cartões segundo a ordem definida como correta. Com o objetivo de avaliar se os participantes aprenderam mais que seqüências e cadeias entre estímulos, isto é, se formavam classes permutando estímulos de acordo com a ordem, Lazar (1977) reorganizou os cartões, apresentando pares de estímulos que não haviam sido apresentados juntos anteriormente, mas diante dos quais os participantes haviam sido ensinados a selecionar um em primeiro e o outro em segundo lugar nas seqüências ensinadas separadamente (ex. A1 $\rightarrow$ B2). Todos os participantes apresentaram resultados positivos nessa avaliação e Lazar (1977) concluiu que o treino tinha estabelecido duas classes, a dos "primeiros" e a dos "segundos". Em seguida, pelo procedimento de pareamento de acordo com o modelo ${ }^{2}$, Lazar (1977) ensinou os participantes a relacionar novos estímulos (E1 e E2) condicionalmente aos estímulos A1 e A2. Em cada tentativa, o estímulo modelo era, ora o A1, ora o A2 e os estímulos de comparação eram os novos estímulos (E1 e E2). A resposta de seleção era conseqüenciada como correta se o participante apontasse E1 (e não E2), quando A1 estava presente, e E2 (e não E1), quando A2 estava presente. Com o objetivo de avaliar se as funções de "primeiro" e "segundo" de A1 e A2 foram estendidas para E1 e E2, respectivamente, Lazar avaliou se os participantes compunham uma seqüência com os novos estímulos (E1 $\rightarrow$ E2). Dois dos três participantes produziram imediatamente as novas seqüências, demonstrando que as funções de controle dos estímulos A1 e A2 foram estendidas aos novos estímulos, e que os participantes passaram a ordenar esses estímulos sem a necessidade de ensino direto das posições que deveriam ser ocupadas por E1 e E2.

Green e colaboradores (1993) descreveram as propriedades das relações ordinais entre estímulos a partir de definições lógico-matemáticas. Uma relação ordinal pode ser representada por códigos alfanuméricos [A1 $\rightarrow$ A2] separados por uma seta (lê-se: A1 é seguido por A2). Dessa forma, uma relação ordinal definida por uma seqüência de $n$ termos é representada por A1 $\rightarrow$ A2 $\rightarrow$ An. As propriedades que definem relações entre estímulos como de natureza ordinal são a irreflexividade, a assimetria, a transitividade e a conectividade. A irreflexividade demonstra que a relação ordinal é explicitamente não reflexiva, isto é, um membro de uma seqüência não pode ser seguido por ele mesmo e, deste modo, não é verdadeiro que A1 $\rightarrow$ A1 (por exemplo, se João é o primeiro da fila, não é verdadeiro que ele venha antes dele mesmo). A 
assimetria indica que a relação ordinal é unidirecional e a relação não continua verdadeira se houver a reversibilidade na ordem de apresentação dos elementos do conjunto como, por exemplo, A1 $\rightarrow$ A2 ${ }^{1}$ A2 $\rightarrow$ A1 (por exemplo, se entre dois irmãos Maria nasceu antes de José, não é verdadeiro dizer que José nasceu antes de Maria). A transitividade é uma propriedade inferida apenas por pares de estímulos não adjacentes, porém estabelecida a partir do ensino serial destes e desde que os pares adjacentes apresentem pelo menos um elemento em comum: se A1 $\rightarrow$ A2 e A2 $\rightarrow$ A3, então A1 $\rightarrow$ A3; por exemplo, se Maria tem nota maior que José, e se José tem nota maior que João, então Maria tem nota maior que João. A conectividade é inferida se a relação entre todos os possíveis pares existentes, adjacentes e não adjacentes, são arranjadas em ordem consistente como, se A1 $\rightarrow$ A2 $\rightarrow$ A3, então A1 $\rightarrow$ $\mathrm{A} 2$, A2 $\rightarrow$ A3, e A1 $\rightarrow$ A3 (por exemplo, se os alunos aprenderem que os feriados do ano estão agendados de forma que a ordem será dia do descobrimento, dia da independência e dia da proclamação da república, então eles podem se tornar capazes de dizer tanto que o dia do descobrimento ocorre antes do dia da independência, quanto que o dia da independência ocorre antes do dia da proclamação da república e que, o dia do descobrimento ocorre antes do dia da proclamação da república, sem terem sido ensinados diretamente a realizar essa tarefa). A descrição operacional das propriedades envolvidas em relações ordinais (Green et al., 1993) permite identificar, por meio de testes comportamentais, se elas estão, de fato, presentes no repertório do aprendiz.

Estudos experimentais baseados no de Lazar (1977) analisaram, com crianças e adultos com desenvolvimento típico e com necessidades especiais, os efeitos do ensino de seqüências compostas por pares de estímulos adjacentes com um elemento em comum, sobre a emergência de novas seqüências com dois ou mais estímulos e sobre a formação de classes de estímulos, cuja propriedade definidora é a ordem de um estímulo em relação a outros estímulos do conjunto, ordem esta definida pelas condições de ensino (Holcomb et al. 1997; Lazar \& Kotlarchyk, 1986; Sigurdardottir, Green, \& Saunders, 1990; Stromer \& Mackay, 1993).

Dentre os estudos que investigaram a emergência de relações ordinais são pertinentes ao contexto deste trabalho àqueles nos quais o procedimento de ensino fundamentouse na utilização de dois estímulos adjacentes com um elemento em comum, em especial, os de Holcomb et al. (1997) e Stromer e Mackay (1993). A questão fundamental nesses estudos foi se o procedimento de ensino empregado (relações seqüenciais entre dois estímulos adjacentes com um estímulo em comum) ofereceria condições para a aprendizagem dessas relações e, também, para a demonstração de relações seqüenciais derivadas das primeiras, assim como para a emergência de novas relações consistentes com o modelo de formação de classes de estímulos definidas pela mesma posição ordinal. Tendo sido ensinadas relações seqüenciais com dois estímulos adjacentes com um estímulo em comum (por exemplo, A1 $\rightarrow$ A2, A2 $\rightarrow$ A3, em que A2 é o estímulo em comum), estes estudos (Holcomb et al. 1997; Stromer \& Mackay, 1993) avaliaram a emergência de relações ordinais derivadas do ensino das primeiras tanto com dois estímulos (ex. A1 $\rightarrow$ A3), assim como com mais de dois estímulos (ex. A1 $\rightarrow$ A2 $\rightarrow$ A3). A formação de classes, por sua vez, foi avaliada misturandose estímulos de diferentes seqüências, assegurando-se que entre os estímulos encontrava-se apenas um de cada posição ordinal. Se estímulos que ocuparam uma mesma posição ordinal em relações ordinais estabelecidas em separado, se mostrassem substituíveis uns pelos outros (Stromer \& Mackay, 1993), isto seria evidência de que estavam sendo tratados em função da posição.

Dado o estabelecimento de relações ordinais A1 $\rightarrow$ A2 $\rightarrow \mathrm{A} 3 \rightarrow \mathrm{A} 4 \rightarrow \mathrm{A} 5$ e B1 $\rightarrow$ B2 $\rightarrow$ B3 $\rightarrow$ B4 $\rightarrow$ B5, Stromer e Mackay (1993) avaliaram se, diante dos estímulos A1, A3, A4, B2 e B5 os participantes selecionariam os estímulos A1 $\rightarrow$ B2 $\rightarrow \mathrm{A} 3 \rightarrow \mathrm{A} 4 \rightarrow \mathrm{B} 5$, em ordem consistente com o treino. Neste exemplo, se na ausência de A2, o estímulo B2 fosse selecionado em segundo lugar, isso indicaria que ambos eram equivalentes quanto à ordem, pois na situação de ensino, A2 e B2 tinham a mesma função ordinal. Os resultados encontrados sugerem que o procedimento de ensino de relações ordinais com pares de estímulos com um elemento em comum estabelece mais do que simples encadeamentos entre estímulos. No encadeamento ${ }^{3}$, a base para a seleção de um estímulo é a presença do estímulo que o antecede na composição da seqüência, o que poderia ter sido estabelecido na situação de ensino. No entanto, quando se avalia a composição de relações ordinais que envolvem a permutação entre estímulos de seqüências diferentes (e que foram diretamente ensinadas em separado), como, por exemplo, quando são apresentados os estímulos A1, A3 e B2, depois de terem sido ensinadas as seqüências $\mathrm{A} 1 \rightarrow \mathrm{A} 2$, A2 $\rightarrow \mathrm{A} 3$, e $\mathrm{B} 1 \rightarrow \mathrm{B} 2$ e B2 $\rightarrow$ B3, o participante pode ser capaz de compor a seqüência $\mathrm{A} 1 \rightarrow \mathrm{B} 2$ $\rightarrow$ A3. Neste exemplo específico, na fase de ensino, o único estímulo que antecedia a seleção do estímulo B2 era o estímulo B1 (A1 era selecionado antes de A2, nunca de B2). Sob tais condições experimentais, a composição da seqüência envolvendo a permutação (A1 $\rightarrow$ B2 $\rightarrow$ A3) sugere que as relações estabelecidas por ensino direto foram mais que encadeamentos de respostas, podendo ser inferida a formação de classes de estímulos definidas pela relação ordinal entre os estímulos (teríamos as classes de estímulos com as funções de primeiro, de segundo e de terceiro). A base da seleção seria a resposta comum apresentada tanto diante de A2, quanto diante de B2, ou seja, selecionar ambos em segundo lugar.

Seguindo essa linha de investigação, o objetivo do presente estudo consistiu em verificar se, tal como nos estudos de Holcomb et al. (1997) e Stromer e Mackay (1993), a aprendizagem e a emergência de relações ordinais seriam igualmente demonstradas com alunos do primeiro ciclo do ensino público fundamental com dificuldades na aquisição de comportamentos acadêmicos e no acompanhamento curricular.

De modo mais específico, o presente estudo teve por objetivos: (a) avaliar a eficácia do procedimento de ensino de pares de relações ordinais compostas por estímulos adjacentes e com um elemento em comum sobre o estabelecimento 
do comportamento de compor as várias seqüências ensinadas (com estímulos do Conjunto A e com estímulos do Conjunto B) e sobre a emergência de relações ordinais com três, quatro e cinco estímulos; (b) avaliar se a aprendizagem de relações ordinais favorece a permutação entre estímulos que exerceram as mesmas funções ordinais em seqüências estabelecidas separadamente e a formação de cinco classes de estímulos definidas pela posição ordinal (os primeiros, os segundos, etc.).

\section{Método}

\section{Participantes}

Os participantes foram cinco alunos do primeiro ciclo do Ensino Público Fundamental com dificuldades no acompanhamento do currículo regular, principalmente na aquisição de leitura e escrita. Dois eram meninos, com idades de 7 e 9 anos e três eram meninas, com idades de 7, 8 e 10 anos, como especificado na Tabela 1. Os alunos foram indicados pelos professores, juntamente com a coordenadora pedagógica, após concordância da escola em acolher o projeto, que tinha como proposta trabalhar com alunos com esse perfil.

A indicação dos professores foi complementada por uma avaliação dos alunos por meio da Wechsler Intelligence Scale for Children III, adaptada para o Brasil (Wechsler, 1997) ${ }^{4}$, para uma medida padronizada. Os resultados, expressos em QI ${ }_{\text {Total }}$ e desempenhos em tarefas verbais (QI verbal $)$ e motoras ou de execução (QI Execução), são apresentados na Tabela 1. Os escores são convergentes com as dificuldades que os alunos estavam apresentando na aquisição de leitura e escrita, isto é, as dificuldades acadêmicas também se traduziram em dificuldades em realizar as tarefas propostas pelo teste (classificações como media baixa e abaixo da média, exceto para o participante ADS, que obteve classificação dentro da média). Quatro dos alunos apresentaram QI verbal (que depende de um ambiente favorecedor do desenvolvimento de linguagem, especialmente de vocabulário, e, inclusive de escolarização) entre 70 e 75; para dois deles (PAL e KTL) esses escores foram claramente menores que os escores de execução, enquanto os outros dois (RNS e RBT) também apresentaram escores de execução rebaixados.

A participação dos alunos teve o consentimento dos pais, concedido em reunião com a coordenadora pedagógica da escola.

\section{Estímulos e tarefa experimental}

A Figura 1 ilustra os estímulos apresentados na tela de um microcomputador, nas etapas de ensino e de avaliação das relações ordinais. Os estímulos, desenhos em preto sobre fundo branco, são considerados como não representacionais, isto é, desprovidos de significado culturalmente pré-estabelecido e são empregados em pesquisas de controle por estímulos visando minimizar eventuais efeitos de história pré-experimental (Lynch \& Green, 1991; Sidman \& Tailby, 1982; Sigurdardottir et al., 1990). Foram empregados dois conjuntos (A e B), cada um com cinco estímulos.

A tarefa do aluno consistia em selecionar os estímulos, posicionando o mouse sobre cada um deles e pressionando a tecla, em seqüência. Nas etapas de ensino, as seqüências

Tabela 1

Caracterização geral dos participantes

\begin{tabular}{|c|c|c|c|c|c|c|c|}
\hline \multirow{2}{*}{ Participantes } & \multirow{2}{*}{ Idade (anos) } & \multirow{2}{*}{ Gênero } & \multirow{2}{*}{ Série Escolar } & \multicolumn{3}{|c|}{ Escores no WISC } & \multirow{2}{*}{ Classificação no WISC } \\
\hline & & & & $\mathrm{QI}_{\text {Total }}$ & $\mathrm{QI}_{\text {Verbal }}$ & $\mathrm{QI}_{\text {Execução }}$ & \\
\hline ADS & 7 & Masculino & $1^{\underline{a}}$ & 97 & 96 & 99 & Dentro da média \\
\hline PAL & 9 & Masculino & $1^{\underline{a}}$ & 83 & 75 & 94 & Média baixa \\
\hline RSN & 7 & Feminino & $1^{\mathrm{a}}$ & 62 & 70 & 62 & Abaixo da média \\
\hline KTL & 8 & Feminino & $2^{\underline{a}}$ & 81 & 75 & 92 & Média baixa \\
\hline RBT & 10 & Feminino & $2^{\underline{a}}$ & 66 & 71 & 67 & Abaixo da média \\
\hline
\end{tabular}

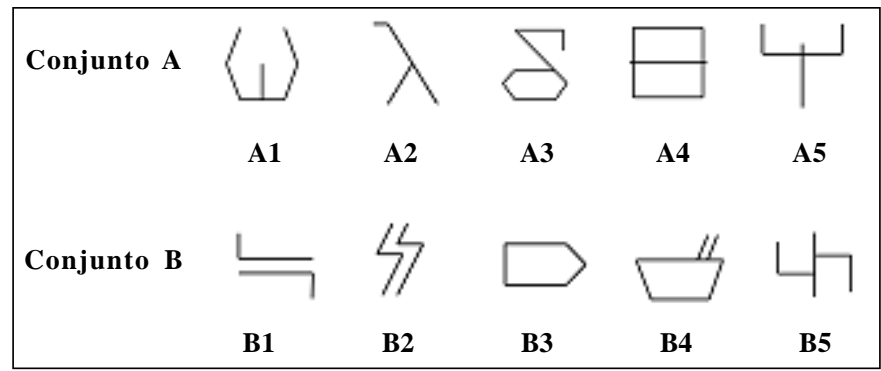

Figura 1. Estímulos empregados nas etapas de ensino e nas sondas de relações ordinais. 
tinham apenas dois componentes; o aluno deveria selecionar um estímulo e depois o outro. Nas sondas para verificação de desempenhos emergentes que poderiam resultar do ensino, o aluno deveria construir seqüências de três, quatro e cinco componentes. Os estímulos, em número correspondente ao da seqüência que estava sendo testada, eram apresentados na tela em ordem aleatória e a tarefa do aluno era ordená-los, selecionando um por vez. Se a ordem era ou não consistente com o ensino, era a questão de interesse no estudo. As respostas do aluno eram registradas automaticamente pelo computador.

Durante as sessões experimentais, que tinham uma duração aproximada de 40 minutos e eram realizadas três vezes por semana, permaneciam na sala somente o aluno e a experimentadora (primeira autora do trabalho). $\mathrm{O}$ aluno sentava-se de frente para a tela, com a mão direita posicionada sobre o mouse. A experimentadora sentava-se atrás e à direita, de modo a observar o desempenho, mas mantendo-se ligeiramente fora da visão do participante.

\section{Materiais e situação de coleta de dados}

As sessões de coleta de dados foram realizadas individualmente em sala cedida pela escola na qual os participantes estudavam. Foi utilizado um programa computacional (Almeida, de Souza, Lopes Jr., \& Caldeiras, 1999) instalado em um microcomputador com monitor (14") colorido. O programa subdividia horizontalmente a tela do monitor em duas partes, como ilustra a Figura 2. A metade inferior consistia na área de projeção das escolhas na qual os estímulos a serem selecionados eram apresentados. A metade superior correspondia à área de construção das seqüências de estí- mulos; nessa área também era apresentado, em posição centralizada, um estímulo cuja função era indicar o início de uma nova tentativa.

\section{Procedimento}

Os participantes foram expostos a condições de ensino e de avaliação para verificação de desempenhos emergentes. A Figura 2 ilustra a configuração de tela, as respostas requeridas e as conseqüências programadas em tentativas de ensino (parte superior) e de teste (parte inferior). Cada tela representa um momento do procedimento, ocorrendo da esquerda para a direita; uma tentativa era iniciada com a apresentação do estímulo na posição central superior da tela ("sinalizador" do início da tentativa) cuja seleção, com o uso do mouse, tinha como conseqüência a apresentação simultânea dos estímulos na área de projeção das escolhas.

Na fase de ensino, a seleção individual dos estímulos de escolha em uma determinada ordem (primeiro um e, em seguida, o outro) acarretava seu deslocamento para a área de construção das seqüências. As tentativas de ensino eram de dois tipos: com ou sem procedimento de correção. Um bloco de tentativas de ensino era sempre iniciado pelo procedimento de correção; quando o critério de aprendizagem era alcançado, o bloco era repetido sem o procedimento de correção. No procedimento de correção, diante de dois estímulos apresentados simultaneamente na área de projeção das escolhas, imediatamente após a seleção de um deles, o desenho selecionado se deslocava para uma posição pré-determinada pelo programa na metade superior da tela. Se o desenho selecionado correspondesse ao arbitrariamente definido como primeiro este permanecia na posição ocupada na área de cons-

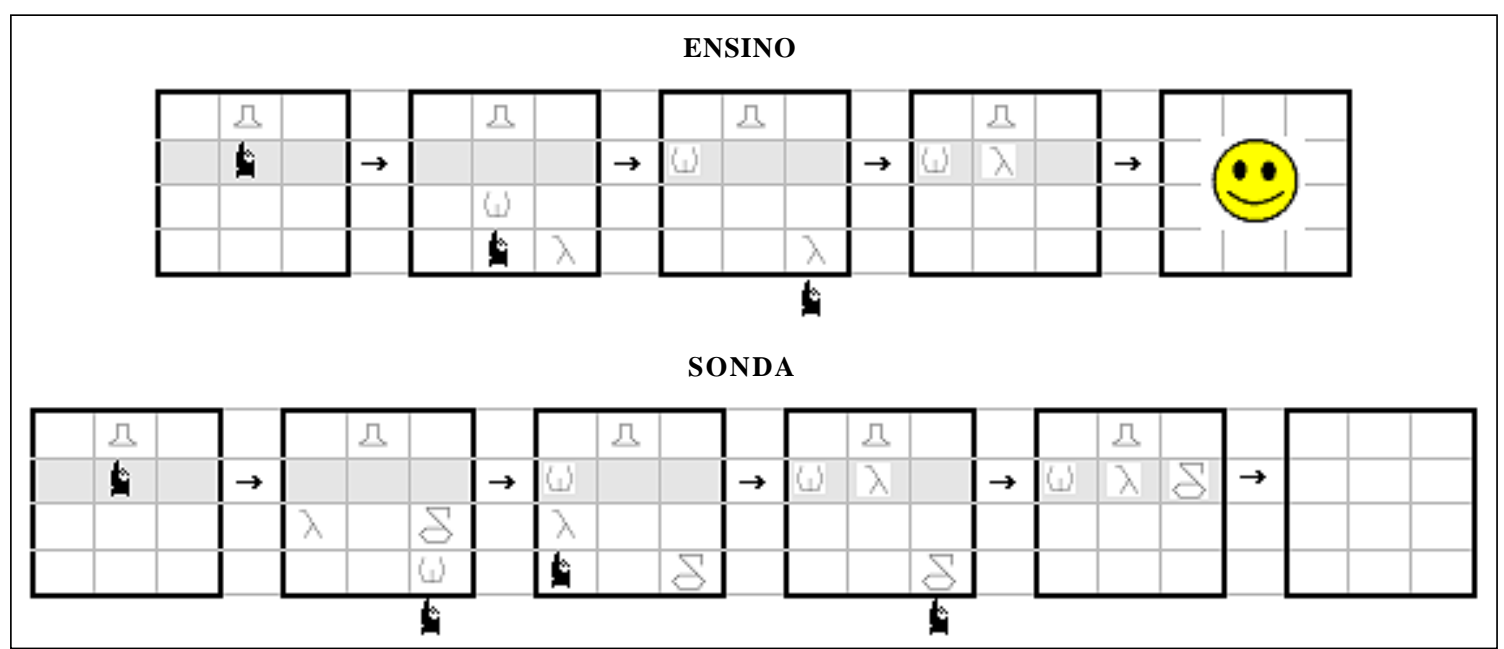

Figura 2. Representação da seqüência do procedimento em uma tentativa de ensino (parte superior) e em uma de sonda (parte inferior). Um clique com o mouse na figura na posição inicial (parte superior central da tela do computador) produzia a apresentação dos estímulos na área de projeção das escolhas (metade inferior da tela). A tarefa consistia em tocar primeiro um estímulo e depois o outro (Ex: A1 $\rightarrow$ A2). Um toque em um estímulo produzia seu deslocamento para a área sombreada na metade superior da tela, até que a seqüência estivesse completa. Na fase de ensino, se a seqüência estivesse correta, a tela apresentava uma conseqüência para acerto (face amarela sorrindo); caso contrário, a tentativa terminava com uma conseqüência para erro (face vermelha triste). Nas sondas a tentativa terminava com a apresentação de uma tela branca. 
trução e o programa apenas voltava a operar quando o participante escolhia o outro desenho. Esta segunda escolha, por sua vez, produzia o deslocamento do segundo desenho para uma posição à direita do primeiro, na área de construção das seqüências. Assim que a seqüência de dois elementos era completada, era apresentada uma tela, com uma face sorrindo (curvatura da boca para cima) sobre fundo amarelo, que indicava que a seqüência estava correta. Diferentemente, caso a primeira escolha recaísse sobre o estímulo definido como segundo, o estímulo era deslocado até a área de construção, na posição definida como segunda e, em seguida, retornava para a posição anteriormente ocupada na área de projeção de escolhas. O participante tinha então a oportunidade de refazer a escolha, selecionando o outro estímulo, o que caracteriza o procedimento de correção. O procedimento de correção permanecia em vigor até que o participante selecionasse os dois estímulos na seqüência definida como correta. No procedimento de ensino sem correção uma composição incorreta acarretava na apresentação da conseqüência para erro (rosto vermelho, triste) e encerrava a tentativa.

Nas tentativas de avaliação da construção de novas seqüências não diretamente ensinadas eram apresentados três, quatro ou cinco estímulos na área de projeção das escolhas e não eram apresentadas conseqüências programadas para acerto ou erro. Cada resposta de seleção produzia o deslocamento do estímulo e ao longo de escolhas sucessivas, cada estímulo ia sendo posicionado na área de construção, à direita do(s) selecionado(s) antes dele (ver Figura 2). Após a seleção do último estímulo remanescente na área de projeção das escolhas e de seu deslocamento para a área de construção, era apresentada uma tela em branco, que sinalizava o intervalo entre tentativas.

As condições de ensino e avaliação foram conduzidas em três etapas resumidas na Tabela 2 e descritas a seguir.

\section{$1^{\underline{a}}$ Etapa: ensino de relações ordinais com dois estímulos adjacentes e com um elemento em comum do conjunto A.}

Sempre que uma nova seqüência de pares de estímulos era ensinada, o procedimento iniciava-se por tentativas com correção. Dessa forma, a primeira exposição às relações (A1 $\rightarrow$ A2), (A2 $\rightarrow$ A3), (A3 $\rightarrow$ A4) e (A4 $\rightarrow$ A5) isoladamente, era iniciada pelo procedimento de correção. No ensino da primeira seqüência (A1 $\rightarrow$ A2), o bloco com procedimento de correção era seguido por um bloco sem correção. Depois do ensino de cada nova seqüência, o bloco sem correção mesclava os tipos de seqüências já ensinadas. O critério de aprendizagem para as relações ensinadas foi definido como a ocorrência de, no máximo, um erro por bloco de tentativas. Se o critério não fosse atingido, era conduzido um novo bloco do mesmo tipo, mas com o procedimento de correção. Independente do número de acertos no bloco com correção, ao finalizá-lo o programa avançava para o bloco seguinte previsto no planejamento de ensino.

O primeiro bloco com procedimento de correção visava ensinar a seqüência A1 $\rightarrow$ A2. Após a terceira tentativa, o programa expunha automaticamente o participante a um bloco de três tentativas sem correção. Se o critério de aprendizagem fosse alcançado neste bloco, o programa avançava para um bloco de três tentativas com correção para ensino da seqüência A2 $\rightarrow$ A3. Após a terceira tentativa, seguia-se automaticamente um bloco sem correção para a mesma relação. Após a obtenção do critério de aprendizagem era apresentado um bloco de seis tentativas sem o procedimento de correção que mesclava, em ordem definida por sorteio, tentativas de construção das duas seqüências recém-ensinadas, A1 $\rightarrow$ A2 e A2 $\rightarrow$ A3. A não obtenção do critério de aprendizagem nesse bloco acarretava a exposição a um novo bloco de com

Tabela 2

Seqüências para construir nas fases de ensino e de avaliação de desempenhos emergentes. As sondas eram inseridas em um bloco de tentativas ensinadas.

\begin{tabular}{|c|c|c|c|}
\hline Condição & $1^{\underline{a}}$ Etapa & $2^{\underline{a}}$ Etapa & $3^{\underline{a}}$ Etapa \\
\hline \multicolumn{4}{|c|}{ Ensino de sequências } \\
\hline $\begin{array}{l}\text { Ensino } \\
\text { Seqüências com dois } \\
\text { estímulos adjacentes e } \\
\text { um estímulo em comum }\end{array}$ & $\begin{array}{l}(\mathrm{A} 1 \rightarrow \mathrm{A} 2) \\
(\mathrm{A} 2 \rightarrow \mathrm{A} 3) \\
(\mathrm{A} 3 \rightarrow \mathrm{A} 4) \\
(\mathrm{A} 4 \rightarrow \mathrm{A} 5)\end{array}$ & $\begin{array}{l}(\mathrm{B} 1 \rightarrow \mathrm{B} 2) \\
(\mathrm{B} 2 \rightarrow \mathrm{B} 3) \\
(\mathrm{B} 3 \rightarrow \mathrm{B} 4) \\
(\mathrm{B} 4 \rightarrow \mathrm{B} 5)\end{array}$ & \\
\hline \multicolumn{4}{|c|}{ Avaliação de desempenhos emergentes } \\
\hline $\begin{array}{l}\text { Sondas } \\
\text { Responder ordinal com } \\
\text { três estímulos }\end{array}$ & $\begin{array}{l}(\mathrm{A} 1 \rightarrow \mathrm{A} 2 \rightarrow \mathrm{A} 3) \\
(\mathrm{A} 2 \rightarrow \mathrm{A} 3 \rightarrow \mathrm{A} 4) \\
(\mathrm{A} 3 \rightarrow \mathrm{A} 4 \rightarrow \mathrm{A} 5)\end{array}$ & $\begin{array}{l}(\mathrm{B} 1 \rightarrow \mathrm{B} 2 \rightarrow \mathrm{B} 3) \\
(\mathrm{B} 2 \rightarrow \mathrm{B} 3 \rightarrow \mathrm{B} 4) \\
(\mathrm{B} 3 \rightarrow \mathrm{B} 4 \rightarrow \mathrm{B} 5)\end{array}$ & \\
\hline $\begin{array}{l}\text { Sondas } \\
\text { Responder ordinal com } \\
\text { quatro estímulos }\end{array}$ & $\begin{array}{l}(\mathrm{A} 1 \rightarrow \mathrm{A} 2 \rightarrow \mathrm{A} 3 \rightarrow \mathrm{A} 4) \\
(\mathrm{A} 2 \rightarrow \mathrm{A} 3 \rightarrow \mathrm{A} 4 \rightarrow \mathrm{A} 5)\end{array}$ & $\begin{array}{c}(\mathrm{B} 1 \rightarrow \mathrm{B} 2 \rightarrow \mathrm{B} 3 \rightarrow \mathrm{B} 4) \\
(\mathrm{B} 2 \rightarrow \mathrm{B} 3 \rightarrow \mathrm{B} 4 \rightarrow \mathrm{B} 5)\end{array}$ & \\
\hline $\begin{array}{l}\text { Sondas } \\
\text { Responder ordinal com } \\
\text { cinco estímulos }\end{array}$ & $(\mathrm{A} 1 \rightarrow \mathrm{A} 2 \rightarrow \mathrm{A} 3 \rightarrow \mathrm{A} 4 \rightarrow \mathrm{A} 5)$ & $(\mathrm{B} 1 \rightarrow \mathrm{B} 2 \rightarrow \mathrm{B} 3 \rightarrow \mathrm{B} 4 \rightarrow \mathrm{B} 5)$ & $\begin{array}{l}(\mathrm{A} 1 \rightarrow \mathrm{B} 2 \rightarrow \mathrm{B} 3 \rightarrow \mathrm{A} 4 \rightarrow \mathrm{A} 5) \\
(\mathrm{B} 1 \rightarrow \mathrm{A} 2 \rightarrow \mathrm{A} 3 \rightarrow \mathrm{B} 4 \rightarrow \mathrm{B} 5)\end{array}$ \\
\hline
\end{tabular}


correção das mesmas relações; a ordem de tentativas de cada relação era definida por sorteio. Ao finalizar o bloco com correção, independente do número de acertos, o participante era exposto, automaticamente, a um bloco sem correção. Atingido o critério, a seqüência A3 $\rightarrow$ A4 era ensinada do mesmo modo: um bloco com correção era seguido por um bloco sem correção. Se o critério de aprendizagem fosse atingido, o bloco seguinte, sem correção, mesclava tentativas das seqüências A2 $\rightarrow$ A3 e A3 $\rightarrow$ A4. Se o critério não fosse atingido, retornava-se ao procedimento de correção; se fosse, prosseguia-se com um novo bloco que mesclava todas as seqüências já ensinadas: A1 $\rightarrow$ A2, A2 $\rightarrow$ A3 e A3 $\rightarrow$ A4. Quando o critério era atingido, era ensinada a última seqüência de dois estímulos A4 $\rightarrow$ A5. Finalmente, quando esta última relação era aprendida, ela era incorporada a um bloco com tentativas A3 $\rightarrow$ A4 e depois a um bloco composto por tentativas com as seqüências A2 $\rightarrow$ A3, A3 $\rightarrow$ A4 e A4 $\rightarrow$ A5. Atingido o critério de aprendizagem neste bloco era introduzido o bloco de Linha de Base Integral, em que todas as quatro seqüências $(\mathrm{A} 1 \rightarrow \mathrm{A} 2$, A2 $\rightarrow$ A3, A3 $\rightarrow$ A4 e A4 $\rightarrow$ A5) eram construídas, sem correção e com a ordem dos tipos de tentativas definida por sorteio. Caso o critério de aprendizagem não fosse atingido introduzir-se novamente o procedimento de correção, seguido por novo bloco sem correção. A obtenção do critério de aprendizagem no Bloco de Linha de Base Integral concluía a etapa de ensino com os estímulos do conjunto A e dava início aos testes nessa fase.

Sondas de relações ordinais com três, quatro, e cinco estímulos do conjunto $A$. Depois que os participantes aprenderam a construir as seqüências com dois estímulos adjacentes e com um estímulo em comum, foram conduzidas sondas para verificar se ocorreria a emergência de novas relações ordinais, consistentes com o ensino, quando um número maior de estímulos fosse apresentado na tela do computador. As sondas com três, quatro e cinco estímulos foram conduzidas separadamente, obedecendo à ordem crescente no número de estímulos. Antecedendo a apresentação de cada etapa de sondas, era conduzido um Bloco de Linha de Base Integral, com probabilidade 0,5 de apresentação de conseqüências programadas para acerto e erro, ou seja, a cada duas tentativas, em média, uma terminava com a conseqüência para a construção da seqüência naquela tentativa (fosse correta ou incorreta). Esse procedimento objetivou manter o desempenho estabelecido na linha de base e familiarizar os participantes com tentativas sem conseqüência programada. As sondas de relações ordinais de três estímulos avaliaram a emergência de três relações diferentes formadas por estímulos adjacentes, segundo a ordem estabelecida pelo treino: $\mathrm{A} 1 \rightarrow \mathrm{A} 2 \rightarrow \mathrm{A} 3, \mathrm{~A} 2 \rightarrow \mathrm{A} 3 \rightarrow$ A4 e A3 $\rightarrow$ A4 $\rightarrow$ A5. Cada relação ordinal era avaliada separadamente em um bloco composto por três tentativas. Em cada tentativa eram apresentados, na área de escolhas, os três estímulos a serem seqüenciados e a posição dos estímulos na metade inferior da tela variava de uma tentativa para outra. Se ocorressem erros nos blocos de sondas era conduzido um novo treino, apenas com as seqüências necessárias para a composição da seqüência que estava sendo avaliada. Por exemplo, se ocorressem erros no teste da relação A3 $\rightarrow$ A4 $\rightarrow$ A5, o programa apresentava automaticamente um bloco composto por A3 $\rightarrow$ A4 e A4 $\rightarrow$ A5, primeiro com correção e, em seguida, sem correção. Após as sondas em separado, era conduzido um bloco com nove tentativas (ver terceira linha da Tabela 2), que mesclava os três tipos de seqüências de três elementos. A seguir, o teste de relações com quatro estímulos avaliou duas relações ordinais diferentes, A1 $\rightarrow$ A2 $\rightarrow$ A3 $\rightarrow$ A4 e A2 $\rightarrow$ A3 $\rightarrow$ A4 $\rightarrow$ A5, sendo cada relação avaliada em um bloco separado, composto por três tentativas e, em seguida mescladas em um único bloco com seis tentativas (ver quarta linha da Tabela 2). Por fim, o teste de relações envolvendo cinco estímulos apresentava todos os componentes do conjunto A e verificava se o participante selecionaria $\mathrm{A} 1 \rightarrow \mathrm{A} 2 \rightarrow \mathrm{A} 3$ $\rightarrow$ A4 $\rightarrow$ A5, nesta ordem.

\section{$2^{\underline{a}}$ Etapa: ensino de relações ordinais com dois estímulos adjacentes e um elemento em comum do conjunto $B$}

Esta segunda etapa objetivou avaliar se os participantes aprenderiam novas relações ordinais com dois estímulos, com elementos de um outro conjunto de estímulos (B) e se o repertório eventualmente aprendido sustentaria a emergência de novas relações controladas pela ordem ou posição dos estímulos na seqüência. Os procedimentos e critérios foram os mesmos empregados na $1^{\mathrm{a}}$ Etapa. Como mostra a segunda linha da Tabela 2, foram ensinadas quatro seqüências com dois estímulos adjacentes com um estímulo em comum: B1 $\rightarrow$ B2, B2 $\rightarrow$ B3, B3 $\rightarrow$ B4, B4 $\rightarrow$ B5. A obtenção do critério de aprendizagem nessa fase era requisito para a avaliação da emergência de relações ordinais com um número maior de estímulos.

Sondas de relações ordinais com três, quatro e cinco estímulos do conjunto $B$. Nesta etapa foi avaliado se os participantes produziriam novas seqüências com três, quatro e cinco estímulos do conjunto B (ver terceira, quarta e quinta linhas da Tabela 2). Os critérios de apresentação dos blocos de testes, de mudança de blocos e a apresentação de conseqüências programadas nos blocos de Linha de Base Integral que precederam as sondas foram os mesmos adotados empregados na $1^{\mathrm{a}}$ Etapa.

\section{$3^{\underline{a}}$ Etapa: sondas de formação de classes por permutação de estímulos dos conjuntos $A$ e $B$}

Nesta etapa objetivou-se verificar a formação de classes de estímulos definidas pelas funções ordinais dos mesmos. Para essa avaliação eram apresentados estímulos dos Conjuntos A e B, assegurando-se que cada estímulo tivesse ocupado uma posição diferente dos demais, nas seqüências construídas na fase de ensino. Infere-se a formação de tais classes pela permutação entre estímulos que exerceram as mesmas funções ordinais nas relações que foram ensinadas 
separadamente, uma vez que uma seqüência composta por estímulos dos dois conjuntos nunca ocorreu na linha de base. Precedendo a exposição ao teste de permutação de estímulos, os participantes eram expostos a um bloco de Linha de Base Integral, com probabilidade 0,5 de apresentação de conseqüência para a tarefa de completar a seqüência. O bloco de sondas era composto por seis tentativas, em que os estímulos, dispostos fora de ordem na área de escolha eram A1, B2, B3, A4 e A5 ou B1, A2, A3, B4 e B5 (ver quarta coluna, últimas duas linhas da Tabela 2). A construção da seqüência correta requeria a permutação entre estímulos dos Conjuntos A e B. Resultados positivos nestes testes seriam consistentes com a emergência de cinco classes de dois estímulos: a classe dos primeiros (A1, B1), dos segundos (A2, B2), dos terceiros (A3, B3), dos quartos (A4, B4) e dos quintos (A5, B5).

\section{Resultados e Discussão}

Este estudo adotou uma proposta de delineamento semelhante à apresentada por Holcomb et al. (1997) para o estabelecimento de relações ordinais entre dois estímulos adjacentes com um estímulo em comum, envolvendo estímulos de dois conjuntos (A e B). O objetivo foi verificar se o ensino de relações ordinais isoladamente se constituiria em condição suficiente para a emergência de novas relações ordinais, bem como para a emergência de permutação entre estímulos, sugerindo a formação de classes de estímulos cuja propriedade em comum, definidora da classe, era a função ordinal de cada estímulo (a posição que ocupava nas seqüências).

\section{Estabelecimento de relações ordinais}

Os resultados demonstraram, de modo geral, que o delineamento e o procedimento de ensino foram efetivos em estabelecer as relações ordinais com dois estímulos, uma vez que todos os participantes aprenderam as relações ordinais ensinadas com dois conjuntos diferentes de estímulos (A e B), totalizando oito diferentes relações. Com exceção de uma participante (RNS), que precisou ser exposta a dois blocos da Linha de Base Integral até alcançar o critério com os estímulos A, todos os demais foram expostos apenas uma vez a esse bloco (que era o final e reunia todas as relações) com os dois conjuntos de estímulos.

Considerando o repertório de entrada dos participantes, que não estavam aprendendo a ler nem a escrever e que também revelaram dificuldades no WISC III, esse resultado, por si só, sugere que os alunos eram capazes de aprender, de focalizar a atenção e de memorizar as seqüências, tanto entre tentativas, como entre sessões experimentais sucessivas. As seqüências eram curtas, os estímulos eram aparentemente simples e distintos um do outro (o que deve ter favorecido a discriminação entre eles) e a resposta requerida consistia em selecionar entre estímulos dispostos na tela (em ordem diferente daquela exigida na tarefa). Apesar da aparente simplicidade, a tarefa contém os rudimentos do responder seqüencial que é requerido na aprendizagem da leitura e da escrita e na matemática; o aluno que não nota a diferença entre B O L O e L O B O ou O L B O não consegue ler palavras simples; o aluno que escreve ptao em lugar de pato e não nota a diferença na seqüência das mesmas letras, não está aprendendo a escrever; de modo análogo, quando se trata de números impressos, 18 não é o mesmo que 81 . Assim, o desempenho estável e sistemático observado para todos os participantes ao final da fase de ensino demonstra, por um lado, que o procedimento ensina e, por outro, que o aluno aprende.

Um aspecto central do procedimento, além do ensino aos pares, parece ter sido a oportunidade de correção, com feedback imediato para acerto e erro. Nas fases iniciais de ensino, quando o aluno selecionava incorretamente um estímulo antes do outro, o estímulo se deslocava para a área de construção, mas não permanecia ali e o aluno continuava sendo exposto à mesma tentativa, até realizar as duas seleções na ordem correta. Atentar para a seqüência correta tinha uma conseqüência adicional, além do acerto imediato: o programa prosseguia com a seqüência de tentativas e o aluno terminava a "lição" mais depressa, o que podia ter um efeito de redução no "custo" do trabalho. A demonstração de aprendizagem por crianças consideradas “incapazes” de aprender (na percepção das professoras), além de confirmar o que a literatura científica tem demonstrado reiteradamente (Gargiulo, 2006; Hallahan, \& Kauffman, 2003; Henley, Ramsey, \& Algozzine, 1999; Koegel \& Koegel, 1995; Sidman, 1985) tem implicações imediatas no cotidiano dos alunos (que se percebem capazes de aprender) e pode afetar a percepção do professor, especialmente se ele acompanha o progresso do aluno, e se passa a tentar, ele próprio, criar condições para que o aluno aprenda o que está sendo ensinado para os demais alunos.

\section{Emergência de novas relações ordinais}

Todos os participantes também mantiveram a linha de base (acertos acima de $90 \%$ nas seqüências ensinadas) durante as fases de sondas com três, quatro, e cinco estímulos. Esse resultado sugere que o controle pelos estímulos e por sua seqüência estava bem estabelecido.

Os resultados das sondas são apresentados Tabela 3 . Na maioria das oportunidades para compor seqüências novas, os participantes apresentaram a emergência de relações ordinais com três, quatro e cinco estímulos, tanto com elementos do conjunto A, quanto do conjunto B. Tomando-se 80 \% de acertos ou mais como critério de emergência de novas relações ordinais, observa-se que esse critério foi atingido em 66 (82\%) das 80 medidas registradas na Tabela 3. Três participantes deixaram de atingir o critério de desempenho emergente diante de apenas um (ADS e PAL) ou dois (KTL) tipos de seqüências: ADS e KTL apresentaram, respectivamente, 75 e 66,6\% de acertos na composição de seqüências de cinco termos; KTL também não atingiu o critério na avaliação conjunta de três seqüências de três estímulos, enquanto PAL deixou de atingir o critério apenas no primeiro bloco de sondas com três estímulos. 
Tabela 3

Porcentual de acertos de cada participante nas sondas de relações ordinais com três, quatro e cinco estímulos dos conjuntos A ( $1^{\underline{\underline{a}}}$ Etapa) e B ( $2^{\underline{a}}$ Etapa) e nas sondas de permutação de estímulos com elementos dos conjuntos A e B ( $3^{\underline{a}}$ Etapa)

\begin{tabular}{|c|c|c|c|c|c|c|c|}
\hline \multirow{2}{*}{ Etapas } & \multirow{2}{*}{ Número de estímulos } & \multirow{2}{*}{ Seqüências avaliadas } & \multicolumn{5}{|c|}{ Porcentual de acertos } \\
\hline & & & ADS & KTL & RSN & PAL & RBT \\
\hline \multirow{8}{*}{$\begin{array}{c}1^{\underline{a}} \\
\text { (Conjunto A) }\end{array}$} & \multirow[t]{3}{*}{ Três } & $\mathrm{A} 1 \rightarrow \mathrm{A} 2 \rightarrow \mathrm{A} 3$ & 100 & 100 & 88,8 & 62,5 & 100 \\
\hline & & $\mathrm{A} 2 \rightarrow \mathrm{A} 3 \rightarrow \mathrm{A} 4$ & 100 & 88,8 & 66,6 & 88,8 & 12,1 \\
\hline & & $\mathrm{A} 3 \rightarrow \mathrm{A} 4 \rightarrow \mathrm{A} 5$ & 83,3 & 100 & 100 & 88,8 & 25 \\
\hline & \multirow{4}{*}{ Quatro } & $\mathrm{A} 1 \rightarrow \mathrm{A} 2 \rightarrow \mathrm{A} 3 / \mathrm{A} 2 \rightarrow \mathrm{A} 3 \rightarrow \mathrm{A} 4 / \mathrm{A} 3 \rightarrow \mathrm{A} 4 \rightarrow \mathrm{A} 5$ & 100 & 77,7 & 77,7 & 83,3 & 55,5 \\
\hline & & $\mathrm{A} 1 \rightarrow \mathrm{A} 2 \rightarrow \mathrm{A} 3 \rightarrow \mathrm{A} 4$ & 100 & 100 & 100 & 100 & 100 \\
\hline & & $\mathrm{A} 2 \rightarrow \mathrm{A} 3 \rightarrow \mathrm{A} 4 \rightarrow \mathrm{A} 5$ & 100 & 100 & 100 & 100 & 100 \\
\hline & & $\mathrm{A} 1 \rightarrow \mathrm{A} 2 \rightarrow \mathrm{A} 3 \rightarrow \mathrm{A} 4 / \mathrm{A} 2 \rightarrow \mathrm{A} 3 \rightarrow \mathrm{A} 4 \rightarrow \mathrm{A} 5$ & 100 & 83,3 & 91,6 & 100 & 83,3 \\
\hline & Cinco & $\mathrm{A} 1 \rightarrow \mathrm{A} 2 \rightarrow \mathrm{A} 3 \rightarrow \mathrm{A} 4 \rightarrow \mathrm{A} 5$ & 100 & 100 & 100 & 100 & 0 \\
\hline \multirow{8}{*}{$\begin{array}{c}2^{\underline{\underline{a}}} \\
\text { (Conjunto B) }\end{array}$} & \multirow[t]{4}{*}{ Três } & $\mathrm{B} 1 \rightarrow \mathrm{B} 2 \rightarrow \mathrm{B} 3$ & 100 & 100 & 50 & 100 & 100 \\
\hline & & $\mathrm{B} 2 \rightarrow \mathrm{B} 3 \rightarrow \mathrm{B} 4$ & 100 & 100 & 55,5 & 100 & 100 \\
\hline & & $\mathrm{B} 3 \rightarrow \mathrm{B} 4 \rightarrow \mathrm{B} 5$ & 100 & 100 & 100 & 100 & 16 \\
\hline & & $\mathrm{B} 1 \rightarrow \mathrm{B} 2 \rightarrow \mathrm{B} 3 / \mathrm{B} 2 \rightarrow \mathrm{B} 3 \rightarrow \mathrm{B} 4 / \mathrm{B} 3 \rightarrow \mathrm{B} 4 \rightarrow \mathrm{B} 5$ & 88,8 & 100 & 77,3 & 100 & 88,8 \\
\hline & \multirow[t]{3}{*}{ Quatro } & $\mathrm{B} 1 \rightarrow \mathrm{B} 2 \rightarrow \mathrm{B} 3 \rightarrow \mathrm{B} 4$ & 83,3 & 100 & 100 & 100 & 100 \\
\hline & & $\mathrm{B} 2 \rightarrow \mathrm{B} 3 \rightarrow \mathrm{B} 4 \rightarrow \mathrm{B} 5$ & 100 & 100 & 83,3 & 100 & 100 \\
\hline & & $\mathrm{B} 1 \rightarrow \mathrm{B} 2 \rightarrow \mathrm{B} 3 \rightarrow \mathrm{B} 4 / \mathrm{B} 2 \rightarrow \mathrm{B} 3 \rightarrow \mathrm{B} 4 \rightarrow \mathrm{B} 5$ & 100 & 83,3 & 100 & 100 & 100 \\
\hline & Cinco & $\mathrm{B} 1 \rightarrow \mathrm{B} 2 \rightarrow \mathrm{B} 3 \rightarrow \mathrm{B} 4 \rightarrow \mathrm{B} 5$ & 75 & 66,6 & 100 & 100 & 88,2 \\
\hline $\begin{array}{c}3^{\underline{a}} \\
\text { (Permuta) }\end{array}$ & Cinco & $\begin{array}{l}\mathrm{A} 1 \rightarrow \mathrm{B} 2 \rightarrow \mathrm{B} 3 \rightarrow \mathrm{A} 4 \rightarrow \mathrm{A} 5 \\
\mathrm{~B} 1 \rightarrow \mathrm{A} 2 \rightarrow \mathrm{A} 3 \rightarrow \mathrm{B} 4 \rightarrow \mathrm{B} 5\end{array}$ & 41,4 & 83,3 & 83,3 & 75 & 16 \\
\hline
\end{tabular}

No entanto, dois participantes (KTL e PAL) apresentaram dificuldades acentuadas, especialmente na construção de seqüências de três componentes, quer a tarefa fosse a composição de apenas uma seqüência ou de três seqüências diferentes. RSN apresentou mais erros com estímulos do conjunto B, enquanto RBT apresentou mais erros com estímulos do conjunto A. Esses dois participantes não atingiram o critério em cinco (31\%) dos 16 testes, mas tenderam a compor corretamente seqüências mais longas (embora RBT também não tenha acertado a composição de seqüências de cinco elementos na $1^{\text {a }}$ Etapa); portanto, apesar da variabilidade nos dados, mesmo esses dois participantes apresentaram desempenho novo, que caracteriza relações ordinais emergentes, na maioria dos testes.

De modo geral, emergência de relações ordinais com três, quatro e cinco estímulos após o treino sucessivo de relações ordinais com dois estímulos com sobreposição replica dados da literatura que demonstram que o estabelecimento de relações ordinais entre pares de estímulos pode dar origem a uma função ordinal para todos os elementos do conjunto (Green et al., 1993; Holcomb et al., 1997; Trabasso, 1975, citado em Breslow, 1981).

No presente trabalho, os desempenhos apresentados por ADS, KTL e PAL, na avaliação das relações ordinais com três estímulos internos dos conjuntos, ou seja, A2 $\rightarrow$ A3 $\rightarrow$ A4 e $\mathrm{B} 2 \rightarrow \mathrm{B} 3 \rightarrow \mathrm{B} 4$, evidenciaram que o ensino de relações ordinais com pares de estímulos estabeleceu mais do que simples encadeamentos de respostas. Ao selecionar os estímulos nessa ordem, na ausência dos estímulos das extremidades (A1 e A5 ou B1 e B5), o participante demonstrava que os estímulos não apresentavam exclusivamente a função discriminativa que o encadeamento requer. Caso se tratasse de um simples encadeamento, a presença de um estímulo exerceria a função de sinalização que seria condição para a apresentação da resposta inicial de composição da relação ordinal e cada estímulo selecionado seria condição para a próxima resposta de seleção. A presença dos estímulos A1 e A5, por exemplo, pode ter fornecido a base para a seleção em tentativas de composição de seqüiências como A1 $\rightarrow$ A2 $\rightarrow$ A3 ou A3 $\rightarrow$ A4 $\rightarrow$ A5. Porém, a composição de seqüências como B2 $\rightarrow$ B3 $\rightarrow$ B4 não tem por base de seleção o estímulo B1, que na fase de ensino teve a função de primeiro; nem tampouco o estímulo B5, com a função de último durante as condições de ensino. Os estímulos apresentados para a composição da seqüência B2 $\rightarrow$ B3 $\rightarrow$ B4 tiveram funções ordinais variadas durante o procedimento de ensino, ora a de primeiro, ora a de segundo. Por esse motivo, a emergência dessa relação reforça a tese de que o procedimento de ensino de relações ordinais entre dois estímulos adjacentes com um estímulo em comum ofereceu condições para o estabelecimento de relações ordinais entre todos os estímulos do conjunto (Green et al., 1993; Stromer, \& Mackay, 1993).

Este estudo estendeu esses resultados prévios para o comportamento de crianças do ensino fundamental com dificuldades de acompanhamento curricular. Com exceção de ADS, todos os demais obtiveram escores abaixo da média na avaliação psicológica. Assim, nem as dificuldades acadêmicas correntes, nem o desempenho na avaliação psicológica foram impeditivos da aprendizagem de relações ordinais en- 
volvendo estímulos de conjuntos distintos, nem da emergência de relações ordinais derivadas das contingências de ensino. Por exemplo, durante a avaliação pelo WISC III, nenhum dos cinco participantes obteve desempenho superior a 6 na contagem ponderada (que varia de zero a 20) no sub-teste “Arranjo de figuras”, pertencente à área de execução, em que uma das principais habilidades envolvidas é organizar figuras segundo uma determinada ordem (Weschler, 1997). No entanto, esses mesmos alunos com baixo desempenho nas tarefas que exigiam responder de acordo com a organização ordinal (seqüencial) de eventos, aprenderam relações de ordem e, mais do que isso, apresentaram comportamento novo, sob controle de relações emergentes, a partir da interação com as condições de ensino e de teste programadas experimentalmente. Essa mudança na composição de seqüências, que passou de incorreta (na avaliação) a acurada (durante o estudo) ocorreu, muito provavelmente, como função do procedimento de ensino, especialmente no que concerne ao ensino sistemático de seqüências de dois estímulos adjacentes com um elemento em comum e ao emprego do procedimento de correção, que favorecia a composição da seqüência correta e evitava que o indivíduo cometesse muitos erros durante o processo de aprendizagem.

Mas mesmo um procedimento de ensino eficaz pode não funcionar igualmente bem com todos os alunos, o que requer análise da interação do comportamento individual com o programa e sua eventual reformulação para atender às necessidades do aprendiz (de Rose, 1999; Sidman, 1985).

Estudos sobre controle de estímulos têm evidenciado que mesmo procedimentos cuidadosos podem favorecer o desenvolvimento de mais de uma topografia de controle de estímulos (McIlvane, Serna, Dube, \& Stromer, 2000), uma vez que relações de controle diferentes para uma mesma resposta, podem levar a um mesmo resultado. No presente estudo pretendia-se estabelecer o controle pela posição de dois estímulos na seqüência; porém cada estímulo tem características próprias, inseparáveis da seqüência, que também podem ter tido um papel na aprendizagem do aluno. Quando este é o caso, é comum que, apesar de uma linha de base acurada e estável, como nesse estudo, o participante não consiga realizar uma tarefa nova que dependa exclusivamente da relação de controle prevista pelo experimentador (e não de qualquer outra que o aluno tenha aprendido). Suponhamos que no presente estudo um aluno tenha aprendido a formar as seqüências sob controle também da configuração final do par de estímulos na parte superior da tela; se isto tiver ocorrido (o que neste momento é passível apenas de especulação), torna-se compreensível a dificuldade de um aluno na composição de seqüências novas de três termos (o que ocorreu com quase todos os alunos, em pelo menos uma das sondas). Como essas aprendizagens de relações “colaterais” podem ser muito variáveis de um participante para outro e de uma relação para outra, elas podem ser fonte de variabilidade nos testes e podem se dissipar rapidamente ou podem perdurar. No presente estudo, as dificuldades com seqüências de três termos, pelo menos nas sondas iniciais, podem ter resultado de topografias de controle de estímulos conflitantes ou concorrentes; como o efeito parece ter se dissipado para a maioria dos participantes, pode-se considerar a hipótese de que prevaleceu o controle pela posição, bem estabelecido experimentalmente, com o conseqüente enfraquecimento de topografias irrelevantes. Por outro lado, para os alunos que continuaram apresentando dificuldades, é possível que topografias de controle irrelevantes tenham continuado interferindo com o desempenho nas sondas (a verificação dessas possibilidades, no entanto, requer investigação empírica).

Os dois alunos que deixaram de atingir o critério na composição de algumas das novas seqüências, RSN e RBT, estão entre os que apresentaram os menores escores no WISC III, tanto nas tarefas de execução, quanto nas tarefas verbais. Se por um lado, a literatura científica demonstra o potencial de aprendizagem de alunos com déficits intelectuais, também há evidências de que essa população apresenta uma propensão a aprender relações idiossincráticas, muitas vezes baseadas em particularidades dos estímulos que entram em uma relação, mas não no estímulo como um todo (o que é denominado, tecnicamente, como controle de estímulos restrito; Bailey, 1981; Lovaas, Schreibman, Koegel, \& Rehm, 1971). A possibilidade de que algum grau de controle restrito tenha sido inadvertidamente instalado na fase de ensino mereceria uma investigação experimental, tanto no sentido de identificar os possíveis controles, quanto no de implementar modificações nas tarefas, com vistas a eliminálos (McIlvane et al., 2000) e, assim, garantir aprendizagem coerente com os objetivos de ensino.

\section{Emergência de permutação entre estímulos}

Quanto às sondas de formação de classes, inferida a partir da composição correta de seqüências de cinco elementos dos dois conjuntos, apresentados juntos pela primeira vez durante as sondas, os escores na Tabela 3 mostram que apenas três dos cinco participantes (KTL, RSN e PAL) realizaram a permutação em níveis compatíveis com as classes de estímulos previstas (classe dos primeiros: A1, B1; classe dos segundos: A2, B2; classe dos terceiros: A3, B3; classe dos quartos: A4, B4; e classe dos quintos: A5, B5).

Esses resultados replicam os obtidos por estudos anteriores (Assis \& Sampaio, 2003; Lima \& Assis, 2003; Stromer \& Mackay, 1993). A emergência da relação A1 $\rightarrow$ B2 $\rightarrow$ B3 $\rightarrow$ A4 $\rightarrow$ A5 também não pode ser atribuída a um possível encadeamento de estímulos, pois os estímulos A1 e B2 nunca haviam ocorrido anteriormente em um mesmo contexto. Portanto, a seleção de B2 diante de A1 prescinde de uma história experimental prévia na qual havia reforço diferencial para tal seleção. Sendo assim, os resultados positivos nos testes que avaliaram a permutação entre estímulos dos conjuntos A e B sugerem que os estímulos que ocuparam a mesma posição ordinal formaram uma classe de estímulos definida exatamente pela função ordinal estabelecida nas condições de ensino. De especial interesse, nesse caso, são os dados da participante RSN que, apesar da dificuldade em seqüenciar três estímulos nas duas etapas prévias, formou consistentemente 
classes ordinais (o que sugere que o controle ordinal foi se fortalecendo mesmo durante os testes).

Dois outros participantes, ADS e RBT, construíram seqüências de cinco termos nas sondas de permutação, porém empregaram ordens diferentes das previstas, o que resultou em porcentagens de acerto muito baixas (respectivamente, 41, 4 e 16\%). Por isso foram realizadas análises mais pormenorizadas de como eles trabalharam nessa tarefa, cujos resultados são apresentados na Tabela 4. A tabela apresenta, para os dois participantes, a freqüência relativa de escolha de cada estímulo segundo a posição na seqüência, nos dois tipos de tentativas de sonda (apresentadas na Tabela 2). As células na diagonal contêm a freqüência relativa nas posições teoricamente consistentes com o treino. Se o responder fosse consistente com o que foi ensinado e com a emergência de classes ordinais, o desempenho perfeitamente acurado seria indicado por $100 \%$ em cada uma dessas células.

No primeiro tipo de sonda o participante ADS apresentou a permutação, selecionando os estímulos na seqüência $\mathrm{A} 1 \rightarrow \mathrm{B} 2 \rightarrow \mathrm{B} 3 \rightarrow \mathrm{A} 4 \rightarrow \mathrm{A} 5$ (100\% e 83,3\% na diagonal); no entanto, no segundo tipo de tentativa, trocou a posição dos dois primeiros estímulos da seqüência, escolhendo A2 antes de $\mathrm{B} 1$ (seus acertos na tabela revelam que a seqüência realizada foi A2 $\rightarrow$ B1 $\rightarrow$ A3 $\rightarrow$ B4 $\rightarrow$ B5). Assim, os resultados sugerem a formação das classes dos terceiros, quartos e quintos estímulos na seqüência, mas não as classes dos primeiros e dos segundos. Apesar dos acertos ao seqüenciar A1 e B2, os erros na seqüenciação de A2 e B1 sugerem falta de controle pela ordem tanto por A1 e A2, quanto por B1 e B2. Uma hipótese seria considerar a ordem de treino das relações ordinais com uma variável de controle, pois as seqüências com os estímulos do conjunto A foram estabelecidas antes das seqüências com os estímulos do conjunto B. Essa ordem de treino poderia ter controlado o desempenho de selecionar primeiro o estímulo do conjunto A (A2) e depois o estímulo do conjunto B (B1). Entretanto, essa hipótese não se sustenta, pois essa inversão não ocorreu quando a participante compôs a seqüência $\mathrm{A} 1 \rightarrow \mathrm{B} 2 \rightarrow \mathrm{B} 3 \rightarrow \mathrm{A} 4 \rightarrow \mathrm{A} 5$.

A participante RBT (participante de maior idade cronológica e com classificação abaixo da média no WISC III) apresentou, com maior freqüência, as seqüências A4 $\rightarrow$ A5 $\rightarrow$ B2 $\rightarrow \mathrm{B} 3 \rightarrow \mathrm{A} 1$ e A1 $\rightarrow$ B4 $\rightarrow$ B5 $\rightarrow$ A2 $\rightarrow$ A3, portanto, inconsistentes com a formação de classes ordinais derivadas do que foi diretamente ensinado. Mesmo essas escolhas, porém, não foram totalmente sistemáticas, como mostra a dispersão de escolhas na Tabela 4.

Algumas hipóteses poderiam ser aventadas para uma melhor compreensão desses resultados. RBT apresentou nítidas dificuldades para o estabelecimento das relações ordinais com três estímulos envolvendo ou não os estímulos das extremidades (A2 $\rightarrow$ A3 $\rightarrow$ A4; A3 $\rightarrow$ A4 $\rightarrow$ A5; B3 $\rightarrow$ B4 $\rightarrow$ B5), mas isto parece ter sido superado, como sugere o excelente desempenho apresentado pela participante em todos os testes com quatro estímulos e no teste com os cinco estímulos do Conjunto B. É possível, portanto, que ela tenha continuado aprendendo ao longo do procedimento, tanto da primeira para a segunda etapa, quanto da fase de ensino para a que incluía as sondas. No entanto, a emergência das novas seqüências entre estímulos de um mesmo conjunto não garantiu a formação de classes, o que sugere que, para essa participante, o ensino de seqüências com dois estímulos adjacentes pode ter estabelecido apenas pares ordenados entre os estímulos e não relações ordinais. A variabilidade nos dados também sugere a possibilidade de que tenha ocorrido controle misto por outras variáveis, como a própria história experimental (o que foi ensinado primeiro...). Como mostra a Tabela 4, a participante parece ter estabelecido relação de ordem considerando separadamente os estímulos dos dois conjuntos, isto é, a propriedade de pertencer a um conjunto (A) ou a outro (B) foi o aspecto ou a dimensão mais importan-

Tabela 4

Matrizes de freqüência relativa de escolha seqüência dos estímulos nas duas sondas de permutação pelos participantes ADS e RBT

\begin{tabular}{|c|c|c|c|c|c|c|c|c|c|c|c|}
\hline \multicolumn{6}{|c|}{ Sonda 1} & \multicolumn{6}{|c|}{ Sonda 2} \\
\hline \multicolumn{12}{|c|}{ Participante ADS } \\
\hline & $1^{\circ}$ & $2^{\circ}$ & $3^{\circ}$ & $4^{\circ}$ & $5^{\circ}$ & & $1^{\circ}$ & $2^{o}$ & $3^{\circ}$ & $4^{\circ}$ & $5^{\circ}$ \\
\hline A 1 & 100 & 0 & 0 & 0 & 0 & B1 & 0 & 100 & 0 & 0 & 0 \\
\hline B2 & 0 & 100 & 0 & 0 & 0 & A2 & 100 & 0 & 0 & 0 & 0 \\
\hline B3 & 0 & 0 & 100 & 0 & 0 & A3 & 0 & 0 & 100 & 0 & 0 \\
\hline A4 & 0 & 0 & 0 & 83,3 & 16,7 & B4 & 0 & 0 & 0 & 100 & 0 \\
\hline A5 & 0 & 0 & 0 & 16,7 & 83,3 & B5 & 0 & 0 & 0 & 0 & 100 \\
\hline \multicolumn{12}{|c|}{ Participante RBT } \\
\hline & $1^{\circ}$ & $2^{\circ}$ & $3^{\circ}$ & $4^{\circ}$ & $5^{\circ}$ & & $1^{\circ}$ & $2^{\circ}$ & $3^{\circ}$ & $4^{\circ}$ & $5^{\circ}$ \\
\hline A 1 & $\mathbf{0}$ & 0 & 0 & 0 & 100 & B1 & 100 & 0 & 0 & 0 & 0 \\
\hline B2 & 33,3 & $\mathbf{0}$ & 55,5 & 11,1 & 0 & A2 & 0 & 33,3 & 0 & 55,5 & 0 \\
\hline B3 & 0 & 33,3 & 11,1 & 55,5 & 0 & A3 & 0 & 0 & 33,3 & 0 & 55,5 \\
\hline A4 & 55,5 & 11,1 & 33,3 & 0 & 0 & B4 & 0 & 55,5 & 0 & 33,3 & 0 \\
\hline A5 & 11,1 & 55,5 & 0 & 33,3 & $\mathbf{0}$ & B5 & 0 & 0 & 55,5 & 0 & 33,3 \\
\hline
\end{tabular}


te no controle de suas escolhas; depois, dentro de cada conjunto, prevaleceu a ordem. Por exemplo, a seqüência B1 $\rightarrow$ B4 $\rightarrow$ B5 é compatível com a propriedade da transitividade, sugerindo que as seqüências aprendidas sustentavam essa propriedade (Green, et al. 1993; Trabasso, apud Breslow, 1981). Stromer e Mackay (1973) também encontraram dados de participantes que compunham seqüências envolvendo estímulos dos conjuntos que participaram do treino separadamente, em vez de demonstrarem desempenhos envolvendo a permutação de estímulos com as mesmas funções ordinais, semelhantes aos resultados de RBT.

Em resumo, nas sondas de formação de classes os resultados foram mistos: três participantes mostraram claramente a emergência de controle pela ordem, mesmo por estímulos que nunca foram apresentados juntos na fase de ensino, mas dois outros não mostraram o mesmo tipo de controle. Esses resultados sugerem, em primeiro lugar e em consonância com os dados de Holcomb et al. (1993), que a emergência de relações ordinais pode ser um resultado previsível do ensino tal como empregado nesses estudos. Em segundo lugar sugerem, também, que a não emergência ou a produção de seqüências diferentes das previstas nos testes de permutação não é necessariamente um problema inerente ao teste de permutação (nem de características dos aprendizes, já que um dos alunos que não formou classes - ADS, era o que tinha melhor classificação na avaliação psicológica), mas que pode decorrer de variáveis a serem identificadas e controladas.

No segundo caso, considerando-se que em pesquisas sobre controle de estímulos em geral, resultados inconsistentes e variabilidade resultam de relações de controle não previstas pelo experimentador (McIvane et al., 2000; Sidman, 1994), pesquisas futuras poderiam abordar variáveis de procedimentos com vistas a garantir uma maior uniformidade nas topografias de controle de estímulos nas condições de ensino, antes de submeter os participantes ao teste de permutação. Entre essas variáveis encontram-se algumas sugeridas pelos próprios dados desse estudo, como a ordem em que as relações são ensinadas, ou outras possibilidades, como ensino concorrente (em vez de sucessivo) entre pares de conjuntos diferentes, o número de pares de estímulos que o aluno aprende a seqüenciar, antes dos testes, etc.

Por outro lado, os resultados positivos apontam importantes implicações para o ensino. Em primeiro lugar, sugerem um procedimento: começar por pequenas unidades de aprendizagem, especialmente com alunos com sérias dificuldades pode ser um caminho seguro para ensinar o aluno a produzir seqüências e a atentar para a posição de eventos em seqüências (e, sobretudo para gerar comportamento novo, não diretamente ensinado). Mesmo o ensino de relações com estímulos desprovidos de significado, como no caso desse estudo, pode gerar importantes subprodutos para o repertório acadêmico do aluno.

Em segundo lugar, o mesmo tipo de procedimento cuidadosamente planejado pode ser empregado com estímulos com conteúdo acadêmico, como os requeridos na aprendizagem de leitura, escrita e matemática (e não só para desempenhos mais rudimentares, como seqüências de letras ou de números, mas para a aprendizagem de relações sintáticas com segmentos mais amplos).

Em terceiro lugar, o ensino pode funcionar como avaliação da capacidade do aluno, tanto para aprender o que é ensinado, como para apresentar comportamento emergente sob controle de relações ordinais. A exemplo do que foi encontrado nesse estudo, melhor do que examinar um escore, o desempenho do aluno na sua trajetória de aprender e de estender o aprendido para situações novas pode ser a evidência de seu potencial de aprendizagem e do ritmo em que aprende.

O conhecimento sobre os processos de aprendizagem que levam aos comportamentos complexos envolvidos em seqüenciar eventos pode fornecer subsídios para uma adequada programação de condições de ensino, para uma análise funcional do aprender e para a capacitação de ou a parceria com professores, com vistas a um ensino mais efetivo na promoção de comportamentos acadêmicos relevantes.

\section{Referências}

Almeida, A. C. M., de Souza, D. G., Lopes Jr., J., \& Caldeiras, A. B. (1999). Desenvolvimento de software para aprendizagem de habilidades perceptivas envolvidas no responder sob controle de relações ordinais em pessoas com necessidades educativas especiais [Resumo]. In Sociedade Brasileira para o Progresso da Ciência (Org.), $51^{\underline{a}}$ Reunião Anual da Sociedade Brasileira para o Progresso da Ciência - Caderno de Resumos (p. 68). Porto Alegre: Autor.

Assis, G., \& Costa, L. (2004). Emergência de relações ordinais em crianças. InterAção em Psicologia, 8(2), 199-216.

Assis, G., Élleres, C., \& Sampaio, M. (2006). Emergência de relações sintáticas em pré-escolares. InterAção em Psicologia, 10(1), 19-29.

Assis, G., \& Sampaio, M. (2003). Efeitos de dois procedimentos de ensino para a formação de classes seqüenciais. InterAção em Psicologia, 7(2), 53-56.

Bailey, S. L. (1981). Stimulus overselectivity in learning disabled children. Journal of Applied Behavior Analysis, 14, 239-248.

Breslow, L. (1981). Reevaluation of the literature on the development of transitive inferences. Psychological Bulletin, 89(2), 325-351.

Carmo, J., \& Prado, P. (2004). Fundamentos do comportamento matemático: a importância dos pré-requisitos. Em M. Hübner \& M. Marinotti (Orgs.), Análise do comportamento para a educação: contribuições recentes (pp. 137-158). Santo André: Esetec.

de Rose, J. C. (1999). Explorando a relação entre ensino eficaz e manutenção da disciplina. In F. P. Nunes Sobrinho \& A. C. B. da Cunha (Orgs.), Dos problemas disciplinares aos distúrbios de conduta: práticas e reflexões (pp. 1-23). Rio de Janeiro: Dunya.

Gargiulo, R. M. (2006). Special Education in contemporary society: an introduction to excepcionality. Belmont, California: Thomson Wadsworth.

Green, G., Stromer, R., \& Mackay, H. (1993). Relational learning in stimulus sequences. The Psychological Record, 43, 599-616.

Hallahan, D. P., \& Kauffman, J. M. (2003). Exceptional learners: introduction to special education. Boston, Massachusetts: Allyn \& Bacon.

Henley, M., Ramsey, R. S., \& Algozzine, R. F. (1999). Characteristics of and strategies for teaching students with mild disabilities. Needham Heights, Massachusetts: Allyn \& Bacon.

Holcomb, W., Stromer, R., \& Mackay, H. (1997). Transitivity and emergent sequence performances in young children. Journal of Experimental Child Psychology, 65, 96-124.

Koegel, R. L., \& Koegel, L. K. (1995). Teaching children with autism. Baltimore: Paul H. Brookes. 
Lazar, R. (1977). Extending sequence-class membership with matching to sample. Journal of the Experimental Analysis of Behavior, 27, 381-392.

Lazar, R., \& Kotlarchyk, B. (1986). Second-order control of sequence-class equivalences in children. Behavioural Processes, 13, 205-215.

Lima, M., \& Assis, G. (2003). Emergência de classes seqüenciais após treino com pareamento consistente. Psicologia: Teoria e Pesquisa, 19(1), 75-84.

Lovaas, O. I., Schreibman, L., Koegel, R., \& Rehm, R. (1971). Selective responding by autistic children to multiple sensory input. Journal of Abnormal Psychology, 77, 211-222.

Lynch, D., \& Green, G. (1991). Development and crossmodal transfer of contextual control of emergent stimulus relations. Journal of the Experimental Analysis of Behavior, 56, 139-154.

McIlvane, W. J., Serna, R. W., Dube, W. V., \& Stromer, R. (2000). Stimulus control topography coherence and stimulus equivalence: reconciling test outcomes with theory. In J. Leslie \& D. E. Blackman (Orgs.), Issues in experimental and applied analyses of human behavior (pp. 85-110). Reno: Context Press.
Maydak, M., Stromer, R., Mackay, H., \& Stoddard, L. (1995). Stimulus classes in matching to sample and sequence production: the emergence of numeric relations. Research in Developmental Disabilities, 6(3), 179-204.

Sidman, M. (1985). Aprendizagem-sem-erros e sua importância para o ensino do deficiente mental. Psicologia, 11(3), 1-15.

Sidman, M. (1994). Equivalence relations and behavior: a research story. Boston: Authors Cooperative.

Sidman, M. \& Tailby, W. (1982). Conditional discrimination vs. matching to sample: an expansion of the testing paradigm. Journal of the Experimental Analysis of Behavior, 37, 5-22.

Sigurdardottir, Z., Green, G., \& Saunders, R. (1990). Equivalence classes generated by sequence training. Journal of the Experimental Analysis of Behavior, 10, 3-15.

Stromer, R., \& Mackay, H. (1993). Human sequential behavior: relations among stimuli, class formation, and derived sequences. The Psychological Record, 43, 107-131.

Wechsler, D. (1997). Escala Wechsler de Inteligência para Crianças - Manual para aplicação e avaliação (Ana Maria Poppovic, Trad.). Rio de Janeiro: Cepa.

${ }^{1}$ A notação alfanumérica é empregada apenas para fins de descrição e não está presente nos estímulos visuais apresentados durante os experimentos. A letra designa o conjunto ao qual o estímulo pertence e o número indica a ordem do estímulo nas tarefas de seqüenciação. A1 $\rightarrow$ A2 deve ser lida como: diante da apresentação de dois estímulos (A1 e A2), respostas corretas consistem em selecionar primeiro o estímulo A1 e, em seguida, o estímulo A2.

${ }^{2}$ Um procedimento no qual as funções discriminativas ( $S^{D}$ e S-delta) dos estímulos de escolha (comparação) são condicionadas por propriedades do estímulo modelo ou condicional (Sidman, 1994).

${ }^{3}$ No encadeamento, a presença de um estímulo da seqüência funciona como estímulo discriminativo para a seleção do próximo, ou seja, informa ou sinaliza a ocasião em que a seleção do estímulo tem maior probabilidade de estar correlacionada com a conseqüência programada (reforço).

${ }^{4}$ Foi empregada a versão do WISC-III (Wechsler, 1997) adaptada para o Brasil, uma vez que a pesquisa foi conduzida entre 1999 e 2000 e a versão padronizada para o Brasil (publicada em 2002) ainda não se encontrava disponível.

Ana Claudia M. Almeida-Verdu, doutora em Educação Especial pela Universidade Federal de São Carlos, é professora assistente no departamento de Psicologia e no mestrado em Psicologia do Desenvolvimento e Aprendizagem, Faculdade de Ciências, Universidade Estadual Paulista, em Bauru, SP. Endereço para correspondência: Departamento de Psicologia/UNESP; Av. Eng. Edmundo Carrijo Coube s/n; Bauru, SP; CEP 17033-360. Tel.: (14) 31036087. E-mail: anaverdu@fc.unesp.br

Deisy das Graças de Souza, pós-doutorada pela University of Maryland Baltimore County (EUA), é professora titular no departamento de Psicologia e no Programa de Pós-Graduação em Educação Especial, Universidade Federal de São Carlos, SP. E-mail: ddgs@power.ufscar.br

Jair Lopes Junior, doutor em Psicologia Experimental pela Universidade de São Paulo, é professor assistente no departamento de Psicologia, no Programa de Pós-Graduação em Educação para a Ciência e no mestrado em Psicologia do Desenvolvimento e Aprendizagem, Universidade Estadual Paulista, em Bauru, SP. E-mail: jlopesjr@fc.unesp.br 